\title{
Colorectal Kaposi Sarcoma
}

National Cancer Institute

\section{Source}

National Cancer Institute. Colorectal Kaposi Sarcoma. NCI Thesaurus. Code C96510.

A Kaposi sarcoma that arises from the colon or rectum. 